\title{
Tailoring the mechanical properties of SU-8/clay nanocomposites: polymer microcantilever fabrication perspective
}

\author{
Hao Chen*a, Vincent Ojijo ${ }^{\mathrm{a}}$, Hastings Cele ${ }^{\mathrm{a}}$, Trudi Joubert ${ }^{\mathrm{a}}$, Suprakas Sinha Ray ${ }^{\mathrm{a}}$, Kevin Land ${ }^{\mathrm{a}}$ \\ ${ }^{\mathrm{a}}$ Materials Science and Manufacturing, Council for Scientific and Industrial Research (CSIR), \\ PO Box 395, Pretoria 0001, South Africa
}

\begin{abstract}
SU-8/Clay nanocomposite is considered as a candidate material for microcantilever sensor fabrication. Organically modified montmorillonite clay nanoparticles are dispersed in the universally used negative photoresist polymer SU-8, for a low cost material, which is also biocompatible. If varying the clay loading of the composite material yields a variation of the Young's modulus, the tailored material stiffness presents an opportunity for fabrication of microcantilevers with tunable sensor sensitivity.

With this microcantilever application perspective, mechanical and thermal properties of the material were investigated. SU-8/Clay nanocomposite samples were prepared with clay loadings from $1 \mathrm{wt} \%-10 \mathrm{wt} \%$. Tensile test results show a general trend of increase in composite modulus with an increase in the clay loading up to $7 \mathrm{wt} \%$, followed by a small drop at $10 \mathrm{wt} \%$. The composite material indeed yields moderate variation of the Young's modulus. It was also found that the thermal degradation peak of the material occurred at $300^{\circ} \mathrm{C}$, which is beyond the operating temperature of typical microcantilever sensor applications.

The fabrication of a custom designed microcantilever array chip with the SU-8/Clay nanocomposite material was achieved in a class 100 cleanroom, using spin-coating and photolithography microfabrication techniques. The optimization of the process for fabricating microcantilever with the SU-8/Clay nanocomposite material is discussed in this paper.

The results of this research are promising for cheaper mass production of low cost disposable, yet sensitive, microcantilever sensor elements, including biosensor applications.
\end{abstract}

Key words: SU-8, Clay, nanocomposite, polymer micro cantilever, MEMS, Biosensor

\section{INTRODUCTION}

SU-8, a negative photoresist, is commonly used in the microelectronics industry and in microfluidics device fabrication. It has recently drawn lots of attention in cantilever ${ }^{1-3}$ and bio-MEMS research due to its biocompatibility ${ }^{4-7}$.

SU-8 is in liquid form at room temperature and it has different formulations with various viscosities. With SU-8 it is possible to spin coat films with thicknesses from more than $1 \mathrm{~mm}$ down to submicron levels. The designed structures can then be defined by UV lithography with a high resolution mask. This material has high mechanical strength and a low Young's modulus making it very suitable for the fabrication of micro cantilever sensors. The low Young's modulus ensures that the cantilevers have increased sensitivity ${ }^{6}$.

In 2003, Calleja et al. ${ }^{7}$ reported the fabrication of polymeric cantilever arrays with SU-8 for biosensing applications. The authors demonstrated a cantilever fabrication method using photolithography with photosensitive polymer SU- 8 and sensing of cystamine. Ransley et al. ${ }^{5}$ also reported a similar fabrication method using SU-8 for a $\mathrm{pH}$ sensing application.

In order to enhance the different functional properties, various micro and nano sized fillers, such as silver ${ }^{8}$, carbon nanoparticles ${ }^{9}$, silica ${ }^{10}$, diondoids, carbon nanotubes and gold nanoparticles ${ }^{11}$ have been incorporated into SU-8. SU-8 silver composite, of up to $40 \mathrm{vol} \%$ silver content, were produced to investigate the photo-polymerization and electrical conductivity by Jiguet et al. ${ }^{8}$. It showed that increasing filler fraction resulted in a decrease in polymerization depth for a given UV exposure, due to the UV absorption and reflection by the silver fillers. However, a drastic increase in electrical

Sensors, MEMS, and Electro-Optical Systems, edited by Monuko du Plessis, Proc. of SPIE Vol. 9257, 92570B @ 2014 SPIE · CCC code: 0277-786X/14/\$18 · doi: 10.1117/12.2066315 
conductivity was found between 5 and $6 \mathrm{vol} \%$ filler fraction, and this allows the composite to have possible application in MEMS with highly UV patternable conducting polymers. Seena and co-workers ${ }^{12,13}$ have reported improvement in the electrical, mechanical and transduction characteristics of piezoresistive microcantilevers made of SU-8-carbon black nanocomposites. The Young's modulus was observed to increase with carbon black loading and the values for 8 vol\% samples were about 30-40\% higher compared to a pure SU-8 sample. On the other hand, the device to device resistance variability of SU-8/Carbon black nanocomposites with different carbon black loading were observed to decrease with increasing concentrations of carbon black and the variability was less than $30 \%$ for samples with carbon black concentrations greater than $8 \mathrm{vol} \%{ }^{13}$.

Clay nanoparticles are widely used nano-filler in polymer nanocomposite technology. These layered silicates which have high surface area to volume ratio (and in some cases high aspect ratio) leads to improvement in mechanical properties ${ }^{14,}$ 15. The improvement in the properties is usually more than that of conventional micro and macro-composites for the same quantity of fillers. They are also readily available and usually of low cost. Structurally, the crystal lattice of the 2:1 phyllosilicates consists of layers made up of two tetrahedrally coordinated silicon atoms, fused to an edge-shared octahedral sheet of either aluminium or magnesium hydroxide. These sheets arrange themselves to form stacks. The layer stacking leads to a regular Van der Waals gap between the platelets called the interlayer or the gallery. During the polymer/clay nanocomposite processing, it is imperative that the clay platelets are either dispersed individually in the polymer matrix (delaminated structure) or the polymer diffuses into the clay galleries (intercalated structure), in order to realise the improvement in properties.

Even though several studies have been reported on various SU-8 composites and their applications, to the best of our knowledge, SU-8/clay composites have not been reported in the literature, particularly, for micro cantilever fabrication. In the current study, clays are used to modify the mechanical properties of the SU-8, with the ultimate aim of tuning the Young's modulus of the composites.

The physical properties of SU-8 depend on the processing conditions, therefore the fabrication parameters, which include spin speed, prebake time, UV exposure time, post exposure bake time and development need to be optimized. The optimization becomes more critical with the incorporation of the fillers that could reflect or absorb the UV light during the exposure. In this work, SU-8/ clay composites were prepared. Differential scanning calorimetry and thermogravimetric analyses were used to monitor the extent of SU-8 cross linking during optimization of process parameters. By using the optimized process parameters, microcantilevers were successfully fabricated using SU-8/clay nanocomposites. The objective of the study was to demonstrate the feasibility of fabrication microcantilever from SU$8 /$ clay nanocomposite and to optimize the processing parameters.

\section{EXPERIMENTAL}

\subsection{Materials}

The polymer matrix used was SU-8 purchased from MicroChem. The montmorillonite clay (C30B) used was commercially obtained from Southern Clay Products, Inc, USA and had been modified with methyl tallow bis-2hydroxyethyl quaternary ammonium.

\subsection{Polymer composite preparation and characterization}

SU-8/clay composites containing 1, 3, 5, 7 and $10 \mathrm{wt} \%$ clay content, were prepared by the dispersion of the clay into SU8 solution via sonication for several hours at room temperature. The obtained composites were then spin coated on silicon wafers, soft-baked, exposed to UV, post exposure baked, developed and ultimately hard baked.

For the optimization of soft bake period, a simple visual observation technique recommended by the supplier of the SU-8 was used. The wafer was removed from the hot plate after designated time $(25,30,45$ and $60 \mathrm{~min})$ and allowed to cool. It was then placed on the hotplate again, and if wrinkles were observed, the heating was continued for more time. This cycle was repeated until the wrinkling was not observable. A soft bake time of $45 \mathrm{~min}$ was sufficient. 
To optimize UV exposure period, the soft-baked specimens were exposed to UV radiation for 1, 2, 5, 10, 20, 30, 45 and $60 \mathrm{~min}$. Thereafter, optimum period was used in the subsequent tests. The exposed specimens were baked at $95{ }^{\circ} \mathrm{C}$ for different periods: $10,15,20,25$ and 30 min while hard bake was done at $200{ }^{\circ} \mathrm{C}$ for $5,10,15,20$ and $30 \mathrm{~min}$.

In order to gauge the extent of cross-linking, differential scanning calorimetry (DSC) analyses were carried out on a DSC-Q2000 instrument (TA Instruments) by heating samples of approximately $5 \mathrm{mg}$ from -20 to $350{ }^{\circ} \mathrm{C}$, at a rate of $10{ }^{\circ} \mathrm{C} / \mathrm{min}$. The heat released during cross-linking reaction which occurred between $100{ }^{\circ} \mathrm{C}$ and $280{ }^{\circ} \mathrm{C}$ was used as a measure of the extent of curing during normal processing, i.e. post exposure bake (PEB), and hard bake (HB). Likewise, thermogravimetric analyses (TGA) were conducted on a TG Q500 (TA Instruments) analyser where the samples were heated under air from room temperature to $900{ }^{\circ} \mathrm{C}$ at a rate of $10^{\circ} \mathrm{C} / \mathrm{min}$.

In order to study structure of the SU-8/clay composites, small angle X-ray scattering (SAXS) analyses were carried out by Anton Paar SAXSess instrument, operated at $40 \mathrm{kV}$ and $50 \mathrm{~mA}$ with line collimation geometry. A CuKa radiation with a wavelength of $0.154 \mathrm{~nm}$ (PANalytical X-ray source) was used. This was complimented with direct observation of the state of dispersion of clays with a transmission electron microscope (TEM) (JEOL TEM model JEM-1230) operated at an accelerating voltage of $80 \mathrm{kV}$. For tensile properties, Instron 5966 tester (Instron Engineering Corporation, USA) with a load cell of $10 \mathrm{kN}$ was used. A single strain rate of $5 \mathrm{~mm} / \mathrm{min}$ was used to stretch the dumbbell-shaped samples according to ASTM 638D standards.

\section{RESULTS AND DISCUSSION}

\subsection{Effect of UV dosage, Post exposure bake(PEB) and hard bake(HB) time}

The processing conditions such as UV dosage, PEB and HB duration have a direct influence on the quality of the crosslinked SU-8 structures. In the case of microcantilevers, the SU-8 remains as a structural component and hence the sidewalls need to be sharp and straight. In addition, the incorporated clay may reflect or absorb the UV light during exposure and therefore affects the degree of cross-linking. Hence the cross-linking needs to be maximized to obtain the optimum mechanical property of the composite. The extent of cross-linking may be gauged from DSC and TGA studies. Figure 1 shows the DSC curves obtained by heating samples that were previously exposed to UV for different lengths of time. Two peaks are discernible from the curves: (i) peaks around $100{ }^{\circ} \mathrm{C}$ to $280{ }^{\circ} \mathrm{C}$, associated with the cross-linking reaction and (ii) peaks around $300{ }^{\circ} \mathrm{C}$, which are due to the degradation of samples. Hardly any exothermic cross-linking peak was observed when the exposure time was less than $30 \mathrm{~min}$. On the other hand, samples exposed for less than 30 min were more susceptible to thermal degradation at around $300^{\circ} \mathrm{C}$, than those exposed for more than 30 min. During UV exposure, photo-acid generators in the resist system absorb photons and produce strong acid catalysts. These acids act as the catalysts in the cross-linking reaction in the subsequent steps of post exposure and hard bake. The extent of cross-linking in these two steps is directly proportional to the amount of acid catalysts generated in the UV exposure stage. Moreover, the appropriate exposure time is also influenced by the thickness of the samples and presence of particles, such as clays that are used in the current study. In the present study, the thickness of the samples ranged from $180 \mu \mathrm{m}$ to $240 \mu \mathrm{m}$, while the clay content was $10 \mathrm{wt} \%$. Less than $30 \mathrm{~min}$ of UV exposure did not result in enough acid catalysts, hence the absence of cross-linking peaks between the temperatures of 100 to $280{ }^{\circ} \mathrm{C}$. Due to low extent of cross-linking, even the thermal stability was lower, hence the peaks observed around $300{ }^{\circ} \mathrm{C}$. Exposing the samples to UV for more than $30 \mathrm{~min}$ increased the concentration of the acid catalysts. There was enough catalyst to occasion crosslinking during PEB with remainder helping in cross-linking reaction during DSC test. 


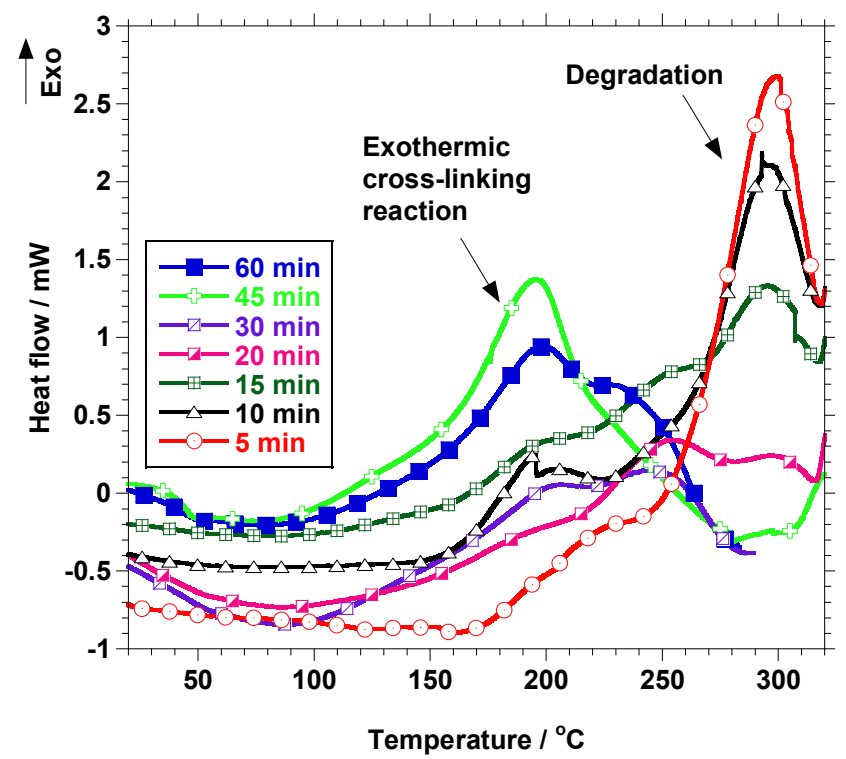

Figure 1. DSC curves for SU-8/clay sample with $10 \mathrm{wt} \%$ clay loading, which had been exposed in UV for different durations

\section{Post exposure bake time}

SU-8/clay $10 \mathrm{wt} \%$ samples exposed in UV for 45 min were baked at $95{ }^{\circ} \mathrm{C}$ for different periods and TGA analyses carried out as illustrated in Figure 2. The thermal stability of the samples improved with bake time until 20 min. Beyond 20 min of PEB, there was no noted improvement in the thermal stability. Therefore, the PEB was fixed at 20 min for subsequent tests.

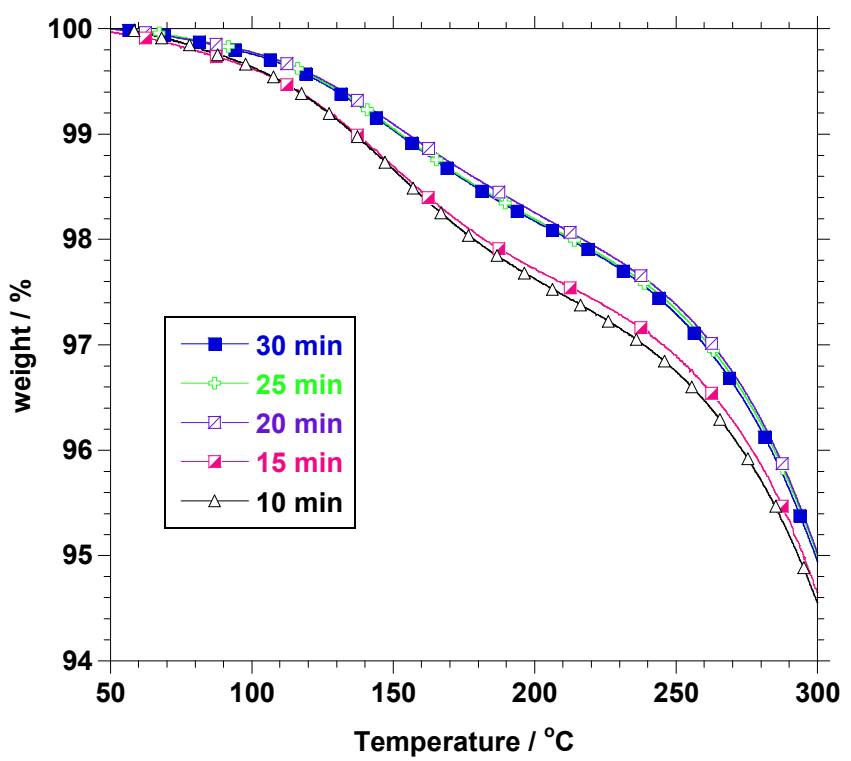

Figure 2. TGA curves of SU-8/10wt\% C30B PEB for different durations, after 45 min of UV exposure

\section{Hard bake time}

Figure 3 shows the DSC curves of SU-8/10wt\% C30B samples hard-baked for different times as well as the enthalpy associated with cross-linking. The HB was shown to increase the extent of cross-linking as shown by the monotonic 
reduction in the cross-linking enthalpy in part (a) and more clearly, in part (a') of Figure 3. After 20 min of HB, only marginal reductions in the enthalpy were observed.

In conclusion, for SU-8 composites containing $10 \mathrm{wt} \%$ clay, a soft bake time of $45 \mathrm{~min}$, UV exposure time of $45 \mathrm{~min}$, PEB time of $20 \mathrm{~min}$ and a hard bake time of $20 \mathrm{~min}$ was found to be optimal. Composites with lower clay concentration were then prepared with same process parameters.
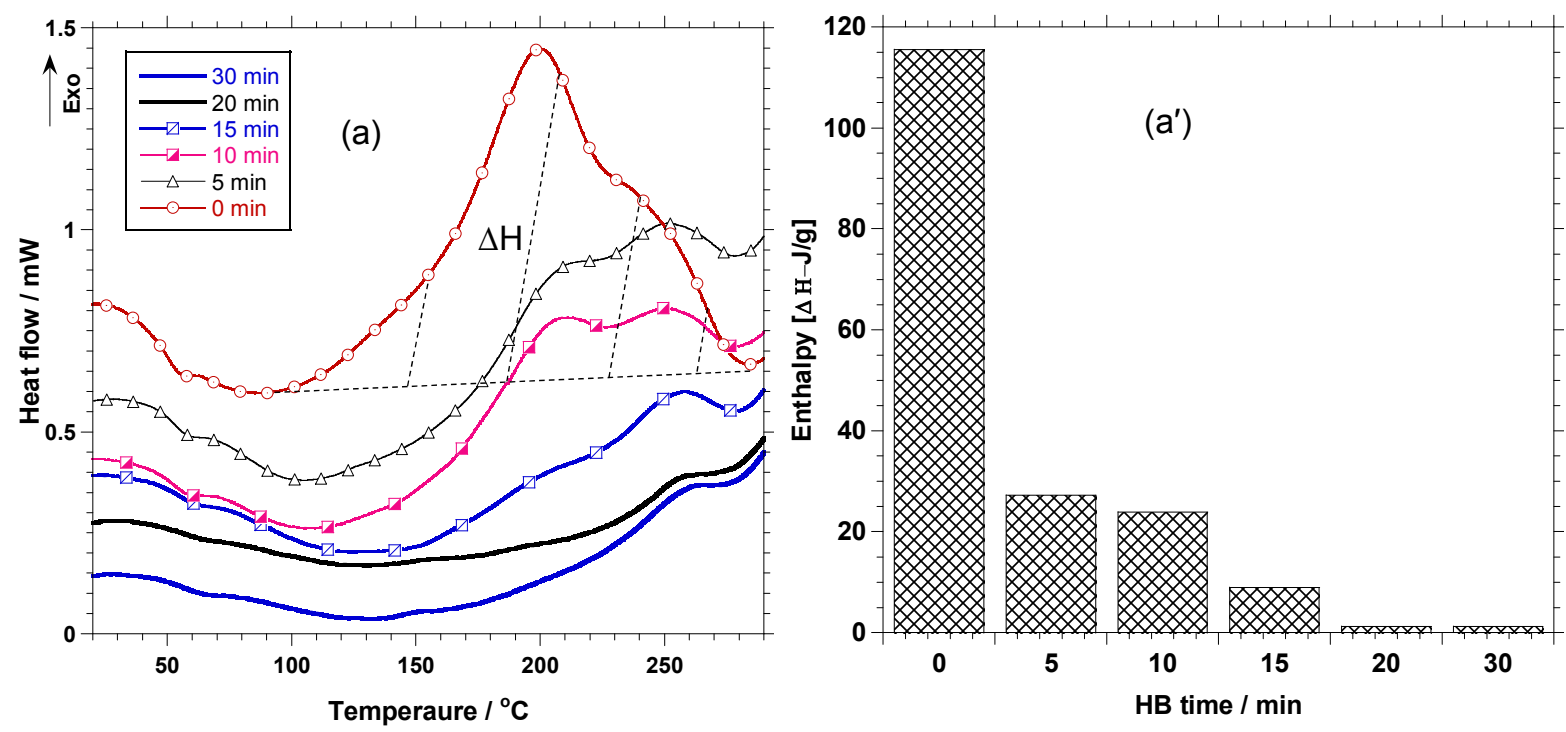

Figure 3. (a) DSC curves of samples hard-baked at $200{ }^{\circ} \mathrm{C}$ for different durations, after 45 min of UV exposure and 20 min of PEB and ( $\left.\mathrm{a}^{\prime}\right)$ enthalpy of cross-linking at temperatures between 100 to $280{ }^{\circ} \mathrm{C}$ as a function of hard bake time

\subsection{Dispersion of clay in SU-8: structural elucidation by SAXS and TEM}

SAXS and TEM studies were carried out to investigate the dispersion of clay in the polymer composites. Figure 4 shows the SAXS patterns of the neat SU-8 and the composites containing different clay contents. For all the composites, the characteristic scattering vector of clay $\mathrm{C} 30 \mathrm{~B}, q$, reduced from 4.83 to $\sim 2.42 \mathrm{~nm}^{-1}$, corresponding to an expansion of the $d_{001}$-spacing from 1.3 to $2.6 \mathrm{~nm}$. This essentially meant that SU-8 molecules intercalated the clays, thereby expanding the gallery spacing between the clay platelets. 


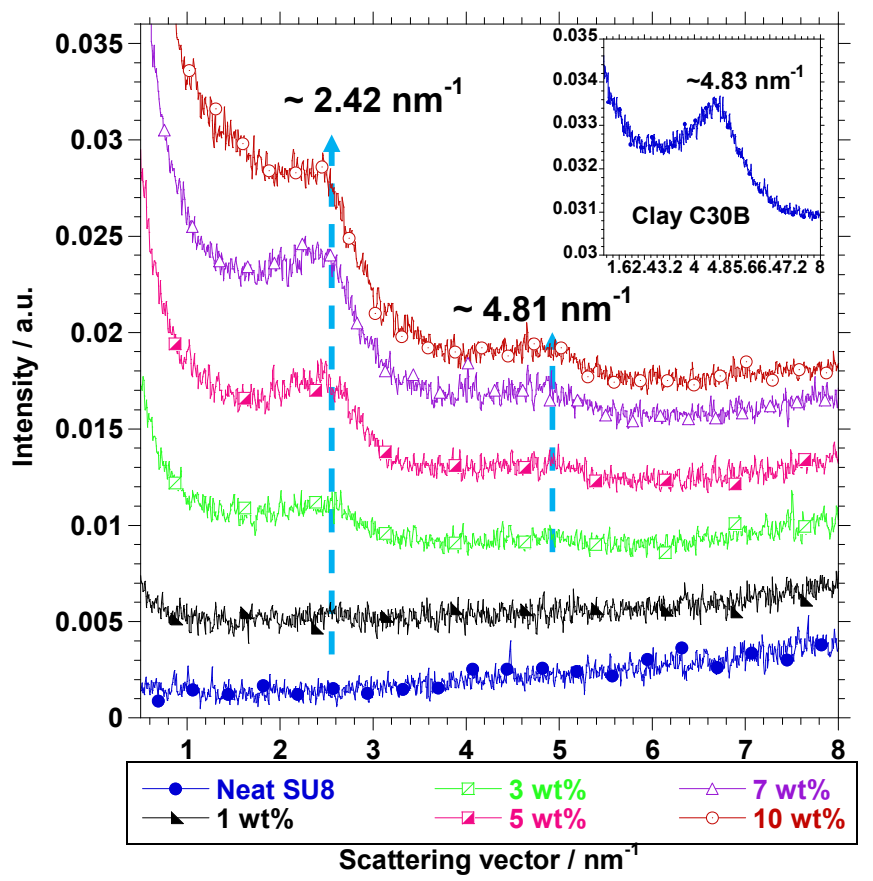

Figure 4. SAXS patterns for SU-8 composites with different clay contents. Increased interlayer spacing suggests intercalated structures

Indeed, the TEM images showed in Figure 5 reveal that the SU-8/clay composites had intercalated structures. Furthermore, the dispersion of the clay particles/tactoids within the SU-8 matrix was uniform, with a few agglomerates at higher clay concentrations. Intercalation and/or delamination of clays as well as uniform dispersion within the SU-8 matrix are a pre-requisite for tuning of the mechanical properties of the composites. 

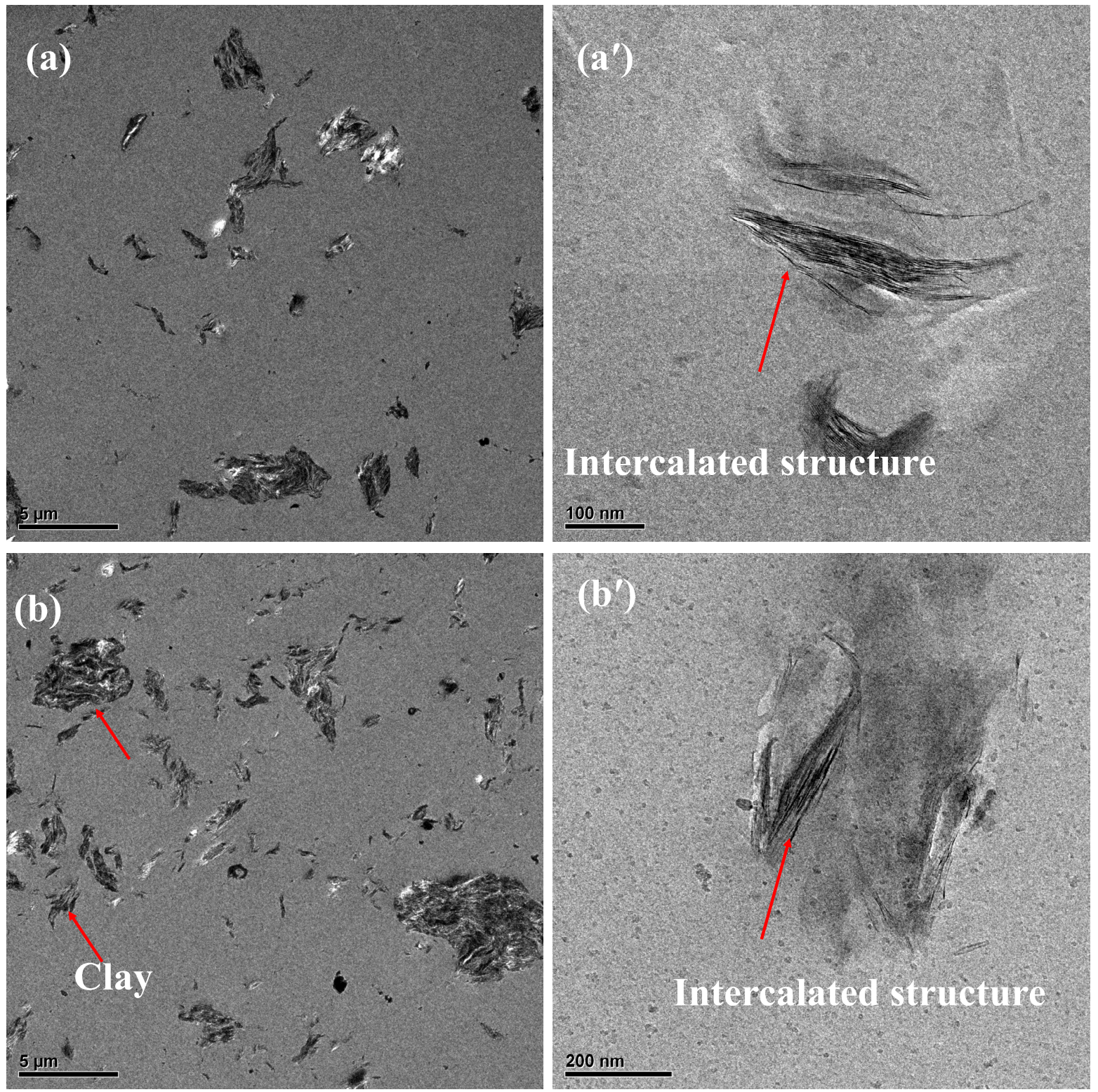

Figure 5. TEM images of SU-8/Clay C30B composites containing (a) $7 \mathrm{wt} \%$ and (b) $10 \mathrm{wt} \%$ of clay. (a') and (b') are higher magnification images of (a) and (b), respectively, showing intercalated structures

\subsection{Effect of clay loading on tensile properties}

Mechanical tests (tensile) were carried out on SU-8/clay composite samples prepared at the previously optimised processing parameters. As shown in Figure 6, there was a general trend of increase in modulus with an increase in the clay content. This increment occurred until a clay content of $7 \mathrm{wt} \%$. Generally, this was the expected result. Clays have higher modulus when compared to SU-8 and hence the modulus increased with increase in clay loading due to the reinforcement effect.

However, at clay loading of over $7 \mathrm{wt} \%$, agglomeration of clays resulted in lower tensile modulus. Therefore, tuning of the modulus of SU-8/clay composites is only possible for the low clay content $(<7 \mathrm{wt} \%)$. 


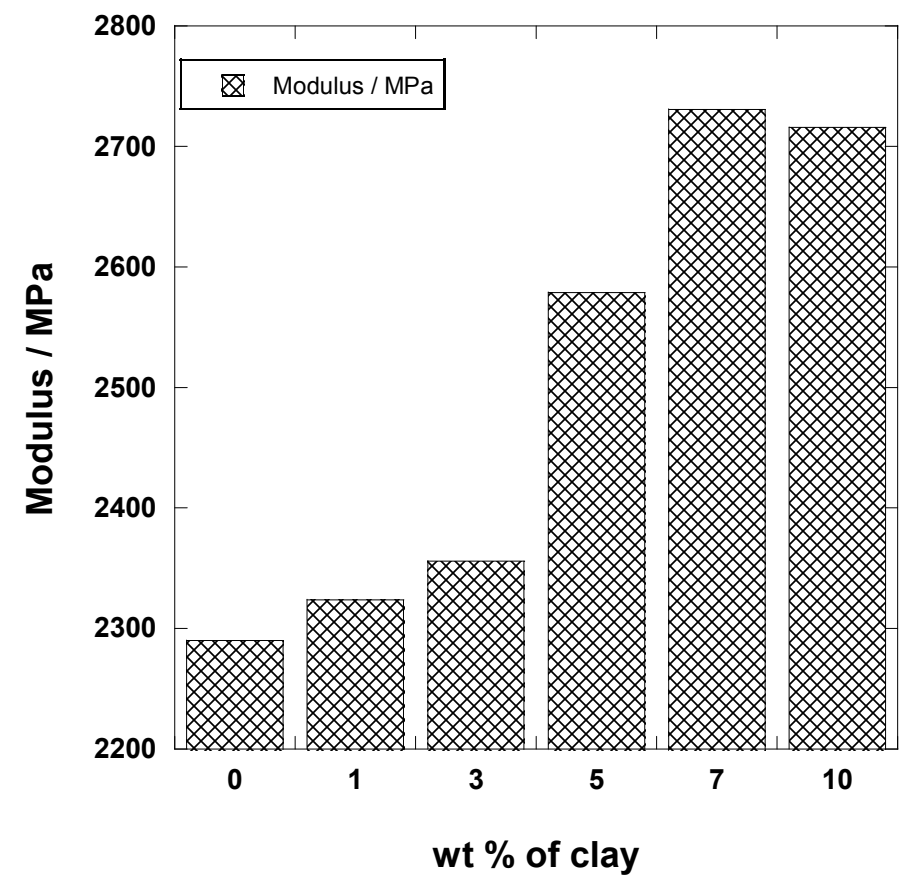

Figure 6. Tensile properties of neat SU-8 and SU-8/Clay composites with filler loadings range $1 \mathrm{wt} \%-10 \mathrm{wt} \%$

\subsection{SU-8/clay cantilever fabrication}

Detailed SU- 8 cantilever fabrication process is shown in Figure 7 below. The mask used in this process has been designed to standard commercial silicon cantilever dimensions with minor modifications being two protection bars added at both ends of the array. These two bars can prevent damaging of the beams during the fabrication process therefore yields a high rate of success in fabrication. The SEM image in Figure 8 below shows a cantilever array with 8 beams made of SU8/clay composite. With this fabrication method, over 200 cantilever chips can be fabricated on a 4 inch wafer therefore the cost of individual chip has been reduced significantly. 
1.)

Wafer

2.)

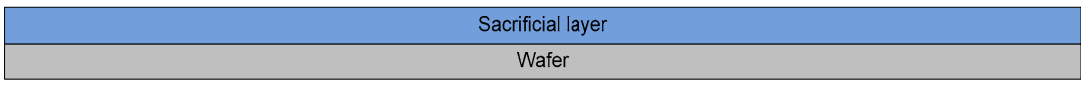

3.)

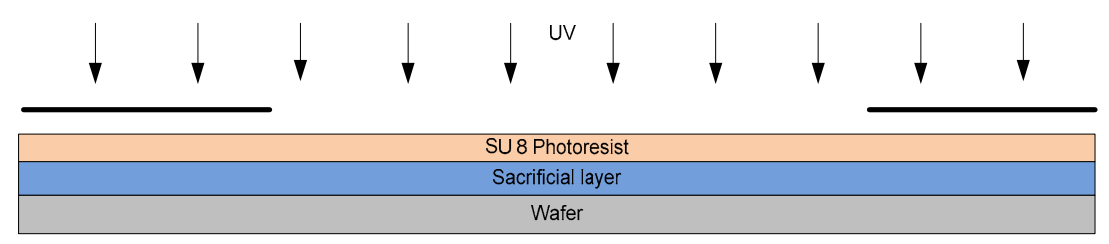

4.)

\begin{tabular}{|c|c|c|}
\hline SU8 & SU 8Exposed & SU 8 \\
\hline \multicolumn{2}{|c|}{ Sacrificial layer } \\
\hline \multicolumn{2}{|c|}{ Wafer } \\
\hline
\end{tabular}

5.)
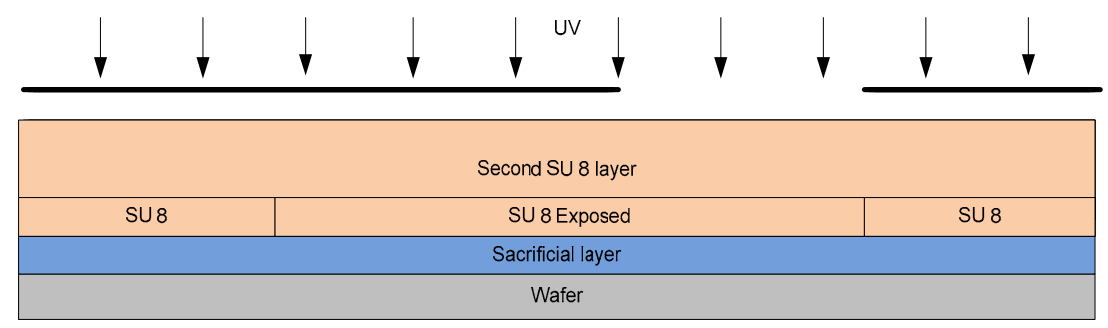

6.)

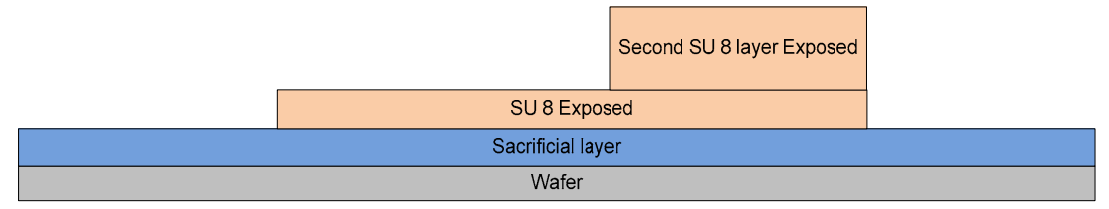

Second SU 8 layer Exposed

SU 8 Exposed

7.)

Wafer

Figure 7. Microcantilever fabrication process showing (1) preparation of silicon wafer (2) spin coating of sacrificial layer (3) spin coating of first layer of SU-8 and exposure (4) cross-linking of exposed SU-8 (5) spin coating of second layer of SU-8 and exposure with second mask (6) developing unexposed SU-8, and (7) etching of sacrificial layer and release of cantilevers 


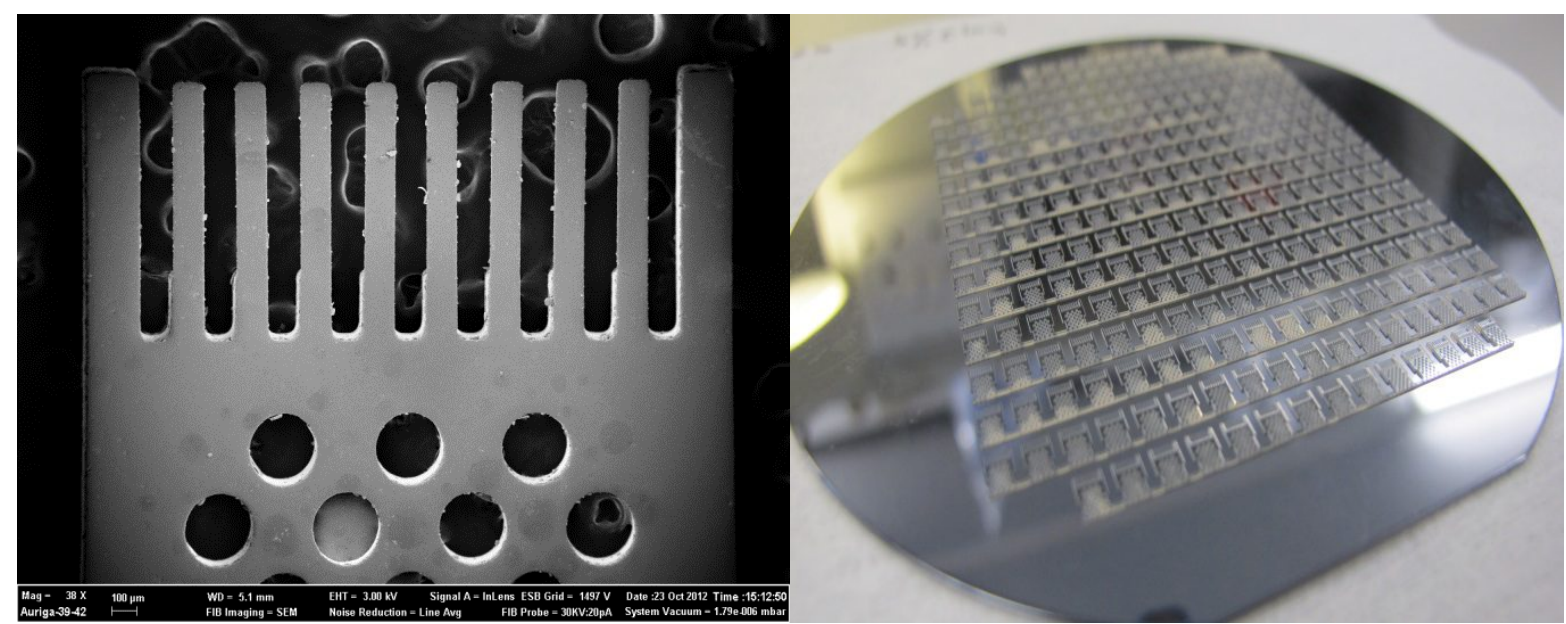

Figure 8. SEM image of micro cantilever fabricated of SU-8/clay 5wt \% composite(left) and 208 SU-8 cantilevers fabricated on one wafer(right)

\section{CONCLUSION}

In this study, the fabrication of microcantilevers using SU-8/clay composites has been demonstrated. SU-8/clay composites with varying Young's modulus were successfully produced. SU-8/clay composites with different filler concentrations $(1-10 \mathrm{wt} \%)$ were prepared and shown to have varying mechanical properties. The mechanical and thermal properties were studied through tensile test, DSC, TGA, and the dispersion of the clay in the polymer matrix was found uniform by TEM study. Sample preparation process was optimized to meet the need for the fabrication of cantilevers. Even though cantilevers with different clay concentration and thickness have also been fabricated successfully, the characterization of the fabricated SU-8/clay microcantilever still needs to be investigated.

\section{ACKNOWLEDGEMENT}

The authors would like to acknowledge TIA and DST for their funding of the project and National Centre for Nano Structured Materials for using of the equipment.

\section{REFERENCE}

[1] Hopcroft, M., Kramer, T., Kim, G., Takashima, K., Higo, Y., Moore, D. and Brugger, J. , "Micromechanical testing of SU-8 cantilevers," Fatigue \& Fracture of Engineering Materials \& Structures 28(8), 735-742 (2005).

[2] Häfliger, D., Nordström, M., Rasmussen, P. A. and Boisen, A. , "Dry release of all-polymer structures," Microelectronic engineering 78, 88-92 (2005).

[3] Luo, C., Govindaraju, A., Garra, J., Schneider, T., White, R., Currie, J. and Paranjape, M. , "Releasing SU-8 structures using polystyrene as a sacrificial material," Sensors and Actuators A: Physical 114(1), 123-128 (2004).

[4] Boisen, A. and Thundat, T. , "Design \& fabrication of cantilever array biosensors," Materials Today 12(9), 32-38 (2009).

[5] Ransley, J., Watari, M., Sukumaran, D., McKendry, R. and Seshia, A. , "SU8 bio-chemical sensor microarrays," Microelectronic engineering 83(4), 1621-1625 (2006). 
[6] Nordström, M., Keller, S., Lillemose, M., Johansson, A., Dohn, S., Haefliger, D., Blagoi, G., Havsteen-Jakobsen, M. and Boisen, A., "SU-8 cantilevers for bio/chemical sensing; fabrication, characterisation and development of novel read-out methods," Sensors 8(3), 1595-1612 (2008).

[7] Calleja, M., Tamayo, J., Johansson, A., Rasmussen, P., Lechuga, L. M. and Boisen, A. , "Polymeric cantilever arrays for biosensing applications," Sensor Letters 1(1), 20-24 (2003).

[8] Jiguet, S., Bertsch, A., Hofmann, H. and Renaud, P. , "SU8-Silver Photosensitive Nanocomposite," Advanced Engineering Materials 6(9), 719-724 (2004).

[9] Lillemose, M., Gammelgaard, L., Richter, J., Thomsen, E. V. and Boisen, A. , "Epoxy based photoresist/carbon nanoparticle composites," Composites Sci.Technol. 68(7), 1831-1836 (2008).

[10] Jiguet, S., Bertsch, A., Judelewicz, M., Hofmann, H. and Renaud, P. , "SU-8 nanocomposite photoresist with low stress properties for microfabrication applications," Microelectronic engineering 83(10), 1966-1970 (2006).

[11] Chiamori, H., Brown, J., Adhiprakasha, E., Hantsoo, E., Straalsund, J., Melosh, N. and Pruitt, B. , "Suspension of nanoparticles in SU-8: Processing and characterization of nanocomposite polymers," Microelectron.J. 39(2), 228236 (2008).

[12] Seena, V., Rajorya, A., Pant, P., Mukherji, S. and Rao, V. R. , "Polymer microcantilever biochemical sensors with integrated polymer composites for electrical detection," Solid State Sciences 11(9), 1606-1611 (2009).

[13] Seena, V., Fernandes, A., Pant, P., Mukherji, S. and Rao, V. R., "Polymer nanocomposite nanomechanical cantilever sensors: material characterization, device development and application in explosive vapour detection," Nanotechnology 22(29), 295501 (2011).

[14] Giannelis, E. P. , "Polymer layered silicate nanocomposites," Adv Mater 8(1), 29-35 (1996).

[15] Sinha Ray, S. and Okamoto, M. , "Polymer/layered silicate nanocomposites: a review from preparation to processing," Progress in polymer science 28(11), 1539-1641 (2003). 